\title{
Computational experiments with a lazy version of a $K$ quickest simple path ranking algorithm
}

\author{
M. Pascoal • M.E. Captivo • J.C. Clímaco
}

Received: 22 June 2007 / Accepted: 22 September 2007 / Published online: 11 October 2007

(C) Sociedad de Estadística e Investigación Operativa 2007

\begin{abstract}
The quickest path problem is related to the classical shortest path problem, but its objective function concerns the transmission time of a given amount of data throughout a path, which involves both cost and capacity. The $K$-quickest simple paths problem generalises the latter, by looking for a given number $K$ of simple paths in non-decreasing order of transmission time.

Two categories of algorithms are known for ranking simple paths according to the transmission time. One is the adaptation of deviation algorithms for ranking shortest simple paths (Pascoal et al. in Comput. Oper. Res. 32(3):509-520, 2005; Rosen et al. in Comput. Oper. Res. 18(6):571-584, 1991), and another is based on ranking shortest simple paths in a sequence of networks with fixed capacity lower bounds (Chen in Inf. Process. Lett. 50:89-92, 1994), and afterwards selecting the $K$ quickest ones.
\end{abstract}

After reviewing the quickest path and the $K$-quickest simple paths problems we describe a recent algorithm for ranking quickest simple paths (Pascoal et al. in Ann.

\footnotetext{
M. Pascoal (凶)

Departamento de Matemática-CIS, Faculdade de Ciências e Tecnologia, Universidade de Coimbra, Apartado 3008, 3001-454 Coimbra, Portugal

e-mail:marta@mat.uc.pt

M.E. Captivo

DEIO-CIO, Faculdade de Ciências, Universidade de Lisboa, Campo Grande, Bloco C6, Piso 4, 1749-016 Lisbon, Portugal

e-mail: mecaptivo@fc.ul.pt

J.C. Clímaco

Faculdade de Economia, Universidade de Coimbra, Av. Dias da Silva, 165, 3004-512 Coimbra, Portugal

e-mail: jclimaco@inescc.pt

J.C. Clímaco

Instituto de Engenharia de Sistemas e Computadores-Coimbra, R. Antero de Quental, 199, 3000-033 Coimbra, Portugal
} 